\title{
laborhifórico
}

ISSN 2359-6910

https://revistas.ufrj.br/index.php/lh/

FONTES PRIMÁRIAS

Recebido em 10 de dezembro de 2020

Aprovado em 15 de janeiro de 2021

\section{As roupas e as mulheres no século XVIII: transcrição paleográfica do documento "Ordem régia à Mesa da Inquisição decretando que não fossem castigadas aleatoriamente as mulheres que comparecessem aos autos religiosos sem as vestimentas adequadas"}

DOI: https://doi.org/10.24206/lh.v7i1.39951

Ana Carolina Alves Caetano

Mestranda em Língua Portuguesa pela Universidade Federal do Rio de Janeiro/ UFRJ.

E-mail: carolina092@outlook.com ORCID: https://orcid.org/0000-0002-2375-3457 


\section{RESUMO}

Esta transcrição tem como principal objetivo apresentar o documento Ordem régia à Mesa da Inquisição decretando que não fossem castigadas aleatoriamente as mulheres que comparecessem aos autos religiosos sem as vestimentas adequadas, e para isso deveriam ser respeitadas diversas condições, evitando assim escândalos desnecessários, datado do período da Inquisição, mais especificamente do ano 1760 . O texto transcrito discorre sobre uma ordem que José I, Rei de Portugal da época, envia à Mesa da Inquisição. O manuscrito encontra-se disponível no acervo digital da Fundação Biblioteca Nacional e na Biblioteca Digital Luso-Brasileira e conta com dois fólios. A transcrição que segue foi feita a partir das normas de transcrição paleográfica presentes na obra de Berwanger e Leal (2015). Devido à importância do conteúdo do registro, acredita-se que a divulgação de uma transcrição do documento possa ser relevante para o conhecimento do texto e para o estudo em diversas áreas, tais como história, linguística, entre outras.

Palavras-chave: Paleografia. Inquisição. Mulheres. Roupas. Século XVIII. 


\section{Introdução}

$\mathrm{O}$ documento editado, neste trabalho, tem como título "Ordem régia à Mesa da Inquisição decretando que não fossem castigadas aleatoriamente as mulheres que comparecessem aos autos religiosos sem as vestimentas adequadas, e para isso deveriam ser respeitadas diversas condições, evitando assim escândalos desnecessários" e está disponível no site da Fundação Biblioteca Nacional e no da Biblioteca Digital Luso-Brasileira. O texto, original e de autoria de José I, Rei de Portugal, https://bdlb.bn.gov.br/acervo/handle/20.500.12156.3/45439, faz parte de um acervo de 1628 documentos que se intitula "Inquisição da Goa".

O manuscrito escolhido aborda a temática da vestimenta das mulheres no período da Inquisição em Portugal. A Inquisição foi

um tribunal que atuou desde o início do século XVI até o começo do XIX, mantendo assim, por quase três séculos, sua ação sobre os cristãos que habitavam Portugal e suas possessões além-mar. (ANDRADE; QUEIROZ 2018, p. 2).

Nesse período, judeus e quaisquer outras pessoas que não obedecessem à Igreja sofriam punições que, muitas vezes, os levavam à morte.

O documento, datado no ano de 1760, trata de uma ordem dada por José I, Rei de Portugal, à Mesa da Inquisição. No texto, o Rei ordena que não sejam presas mais as mulheres que se dirigirem aos atos de fé com roupas inadequadas. José I reivindica, então, que essas mulheres sejam entregues a alguém de "boa reputação", o que acaba por evidenciar a condição vivida pelas mulheres no século vigente. Ele pede, também, que, caso haja alguma dúvida em como agir, seja solicitada a sua presença a fim de que ele possa decidir o que será feito. Além disso, o Rei recomenda que as ações sejam feitas de forma cautelosa, de modo a evitar escândalos. O texto tem, então, caráter imperativo, uma vez que é evidente a ordem dada pelo Rei aos inquisidores.

Calainho e Tavares (2015) afirmam, em relação aos documentos desse período e disponibilizados no acervo digital da Fundação Biblioteca Nacional, que "aquela massa documental tem de ser explorada de maneira mais sistematizada para se tornar base de um maior conhecimento sobre o funcionamento do tribunal goês." (CALAINHO; TAVARES, 2015, p. 7) Sendo assim, a transcrição dessa Fonte Primária tem como objetivo divulgar esse importante documento que marca a história não só da Inquisição como evidencia a condição da mulher no século XVIII. Acredita-se que, a partir

\footnotetext{
${ }^{1} \mathrm{O}$ termo refere-se a "uma instituição que procurou controlar as consciências e o comportamento das populações estabelecidas nos domínios portugueses do Oriente.” (FARIA, 2010, p. 2)
} 
dessa transcrição, outros pesquisadores, tais como historiadores e sociólogos, possam se valer do documento para estudar a figura da mulher e de seu tratamento na inquisição.

A Fonte Primária está organizada em nove seções: resumo, introdução, normas de transcrição, fac-símile e transcrição, considerações finais e referências. Abaixo, encontra-se a ficha catalográfica do documento a fim de facilitar a visualização de suas informações.

\begin{tabular}{|c|c|}
\hline $\begin{array}{l}\text { Quadro 1: Ficha técn } \\
\text { castigadas aleatoriamente } \\
\text { para isso deveriam ser res }\end{array}$ & $\begin{array}{l}\text { do documento Ordem régia à Mesa da Inquisição decretando que não fossem } \\
\text { mulheres que comparecessem aos autos religiosos sem as vestimentas adequadas, e } \\
\text { tadas diversas condiçôes, evitando assim escândalos desnecessários. }\end{array}$ \\
\hline Data & 24 de março de 1760 \\
\hline Tipologia textual & Lei \\
\hline Autor & José I, Rei de Portugal \\
\hline Fonte arquivística & $\begin{array}{l}\text { 25,1,009 n.029 - Manuscritos. Disponível em: } \\
\text { http://acervo.bndigital.bn.br/sophia/index.asp?codigo_sophia=34150 }\end{array}$ \\
\hline Testemunho & Original \\
\hline Registro & $\begin{array}{l}\text { Manuscrito. Documento feito em } 2 \text { vias e remetido anexo ao documento } \\
\mathrm{n}^{\circ} 31\end{array}$ \\
\hline Estado de conservação & Bom \\
\hline Número de fólios & 2 \\
\hline
\end{tabular}




\section{Normas de transcrição}

Para este trabalho, utilizaram-se as Normas Técnicas para Transcrição e Edição de Documentos Manuscritos presentes na obra Berwanger e Leal (2015) para a transcrição do documento. Algumas adaptações foram feitas graças à natureza do documento. Vale ressaltar que os exemplos encontrados foram retirados do texto ou adaptados quando necessário.

(1) Foram separadas as palavras grafadas unidas indevidamente e unidas as sílabas ou letras grafadas separadamente, mas de forma indevida. Excetuaram-se as uniões dos pronomes proclíticos (Seponhão) às formas verbais de que dependem. ${ }^{2}$

(2) As letras foram grafadas na forma usual, independentemente de seu valor fonético.

(3) Os números romanos foram reproduzidos de acordo com a forma da época.

(4) Nos enganos, omissões, repetições e truncamentos, que comprometem a compreensão do texto, foi posta a palavra latina $[s i c]$, entre colchetes e grifada.

(5) As abreviaturas não correntes foram desenvolvidas com os acréscimos em itálico.

(6) As abreviaturas ainda usuais na atualidade ou de fácil reconhecimento foram mantidas.

(7) O sinal de nasalização ou til, quando com valor de m e n, foi mantido.

(8) Quando a leitura paleográfica de uma palavra foi duvidosa, colocou-se uma interrogação entre colchetes depois da mesma: [.......?]. Exemplo: [Palhavãa?]

(9) A acentuação foi mantida conforme o original.

(10) A pontuação original foi mantida.

(11) As maiúsculas e minúsculas foram mantidas.

(12) A ortografia foi mantida na íntegra, não se efetuando nenhuma correção gramatical.

${ }^{2}$ Não foram encontradas formas enclíticas ou mesoclíticas no documento. 
(13) As assinaturas em raso (ou por extenso) e rubricas foram transcritas em grifo.

(14) Os sinais públicos foram indicados entre colchetes e em grifo: [sinal público]

(15) Os selos, sinetes, lacres, chancelas, estampilhas, papéis selados ou desenhos foram indicados de acordo com a sua natureza entre colchetes e grifado: [estampilha]

(16) Os dizeres impressos e o valor das estampilhas foram transcritos dentro de colchetes e em grifo: [55 rs.].

(17) A transcrição dos documentos foi feita linha por linha conforme o original.

(18) Foi respeitada a divisão paragráfica do original.

(19) Os fólios foram numerados pelo transcritor, indicando-se sempre a mudança de cada uma, entre colchetes e em grifo, incluindo-se o verso: [fl. 1], [fl. 2v]. 


\section{O documento e a transcrição paleográfica}

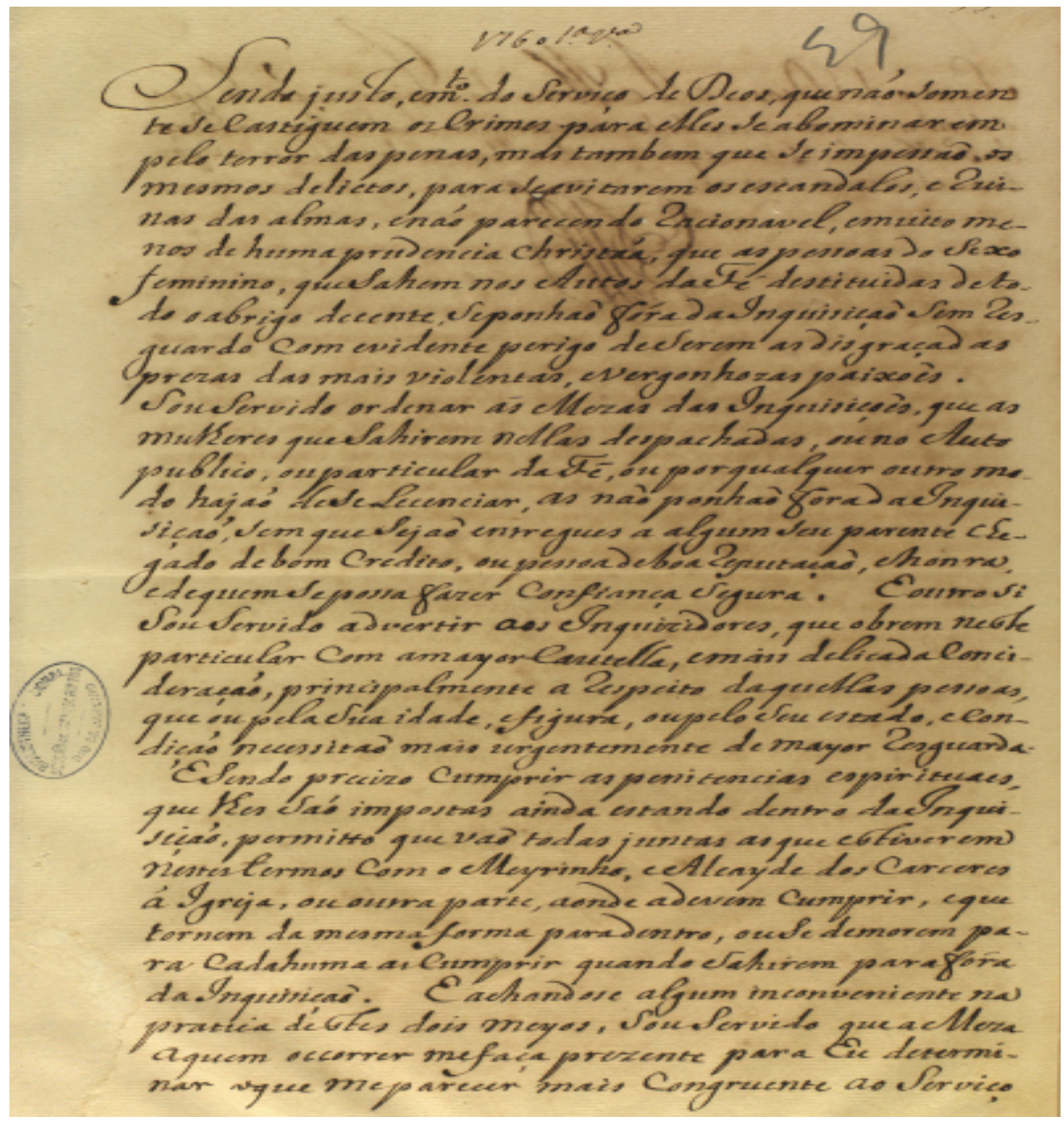




\section{[fl.1]}

Sendo justo, e muito do Serviço de Deos, que não somen te secastiguem os crimes para elles se abominar em pelo terror das penas, mas tambem que se impessão os mesmos delictos, para $\mathrm{se}^{4}$ evitarem os escandalos, e Ruinas das almas, enão parecendo Racionavel, e muito menos de huma prudencia christaã, que as pessoas do Sexo feminino, que sahem nos Autos da Fé destitiídas de todo o abrigo decente, Seponhão fora da Inquisição sem Resguardo com evidente perigo de Serem as disgraçadas prezas das mais violentas, e vergonhozas paixões.

Sou Servido ordenar as Mezas das Inquisições, que as mulheres que sahirem nellas despachadas, ou no Auto publico, ou particular da Fé, ou por qualquer outro modo hajão de se lecenciar, as não ponhão fora da Inquisição, rem que sejão entregues a algum seu parente chegado de bom credito, ou pessoa de boa Reputação, e honra, ${ }^{5}$ e de quem sepossa fazer confiança segura. E outro si Sou servido advertir aos Inquizidores, que abrem neste particular com amoyor cautella, e mais delicada concideração, principalmente a Respeito daquellas pessoas, que ou pela sua idade, e figura, ou pelo seu estado, e condição necessitão mais urgentemente de mayor Resguarda'E sendo precizo cumprir as penitencias espirituaes, que lhes são impostas ainda estando dentro da Inquisição, permitto que vão todas juntas as que estiverem nestes termos com o Meyrinho, e Alcayde de Carceres à Igreja, ou ourra parte, aonde a devem cumprir, e que tornem da mesma forma para dentro, ouse demorem para cada huma as cumprir quando sahirem para fora da Inquisição. E achando se algum inconveniente na pratica destes dois meyos, Sou Servido que a Meza a quem ocorrer mefaça prezente para Eu determinar o que meparecer mais congruente ao Serviço

\footnotetext{
${ }^{3}$ Número 55 escrito a lápis na margem direita do documento.

${ }^{4}$ Há um furo no papel após esse vocábulo

${ }^{5}$ Carimbo com a seguinte frase: BIBLIOTECA NACIONAL SEÇÃO DE MANUSCRITOS RIO DE JANEIRO.
} 


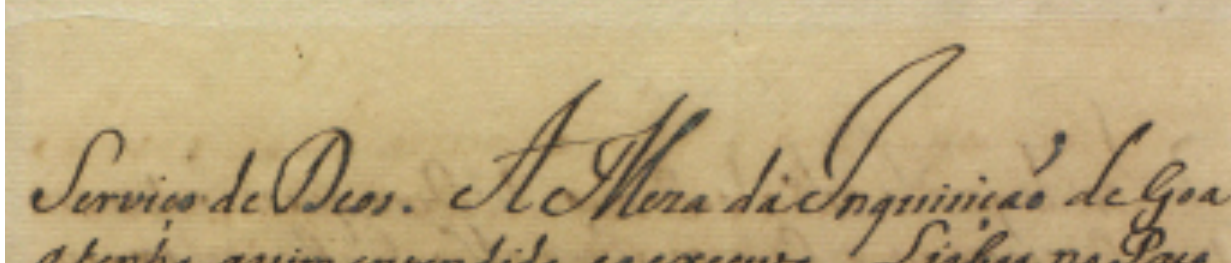

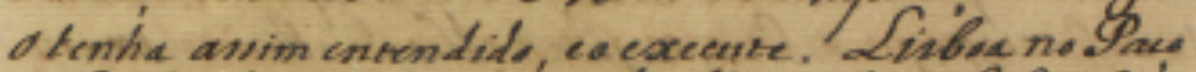

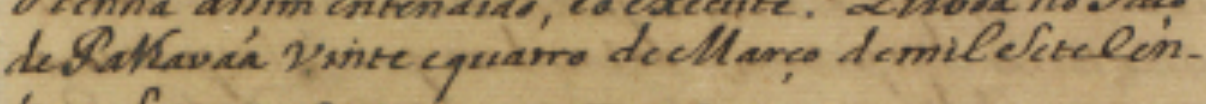
tos celesenta anver.

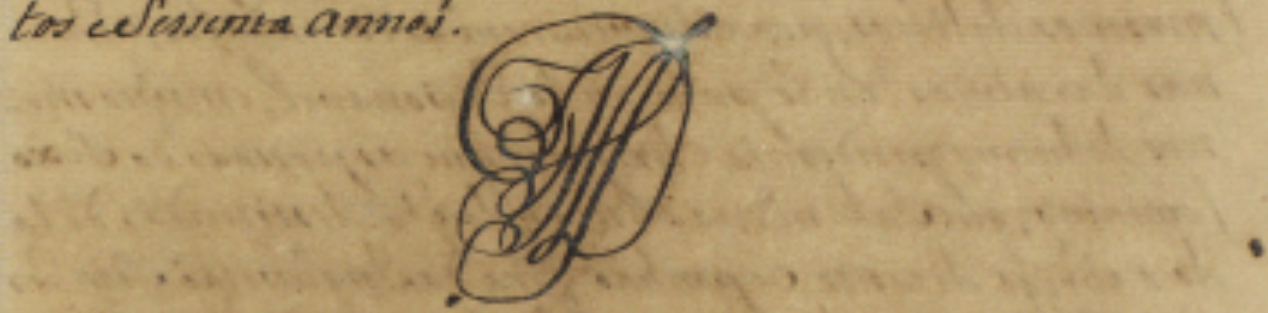

$+1$

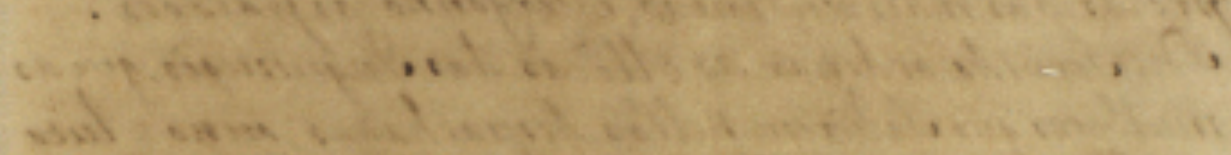

$+$

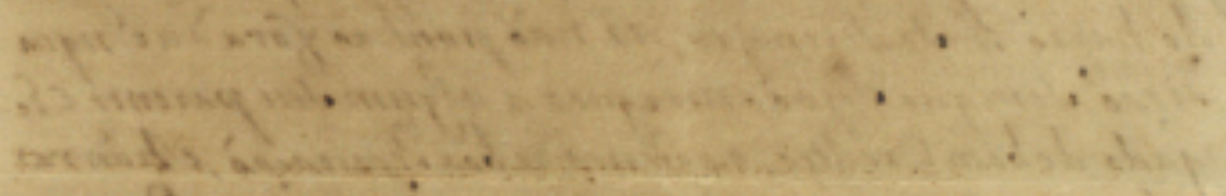

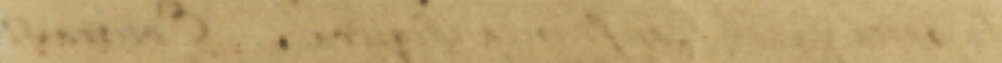

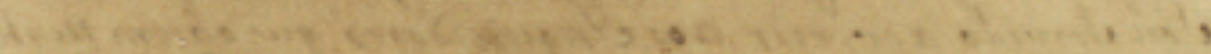

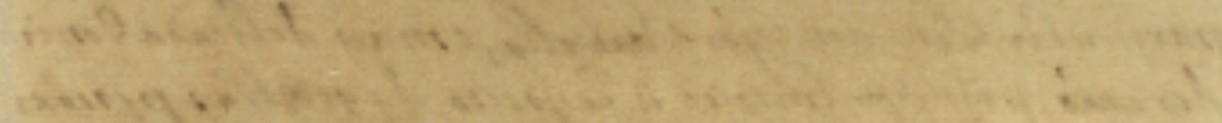

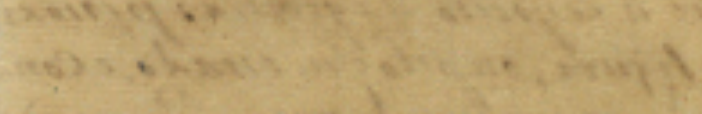

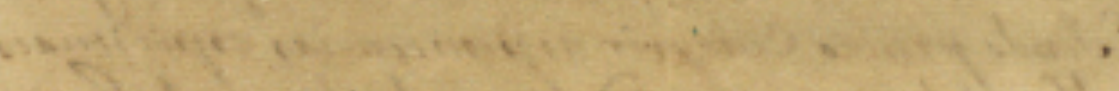

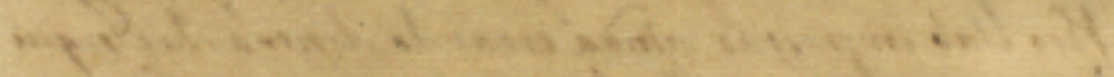

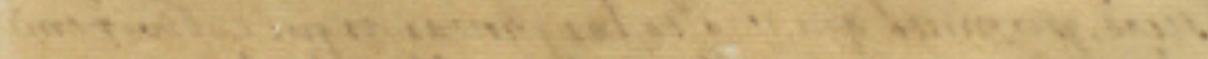

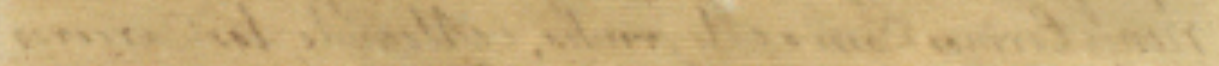

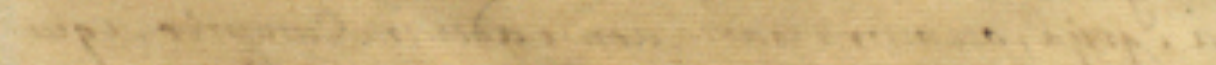

$\cdot 6$

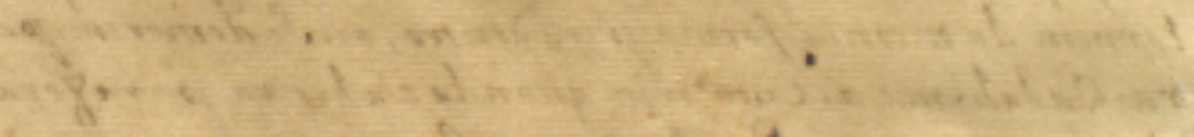

a's

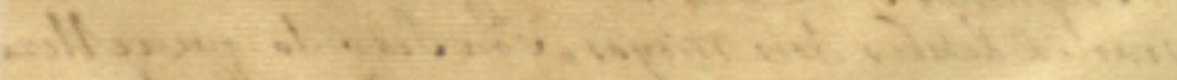

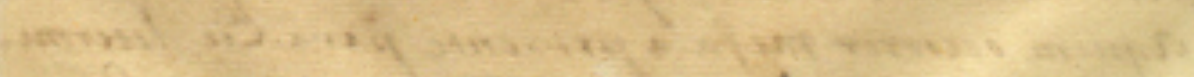


[fl. 2]

Serviço de Deos. A Meza da Inquisição de Goa

o tenha assim entendido, e o execute. Lisboa no Paço

de [Palhavãa?] vinte e quatro de Março de mil e setecen-

tos e sessenta annos.

$[\text { sinal público }]^{6}$

${ }^{6}$ Assinatura em formato de rubrica não identificada totalmente. 


\section{Referências bibliográficas}

ANDRADE, P. G.; QUEIROZ, J. S. de. A inquisição portuguesa e a intolerância religiosa: Os cristãos-novos e a criação do Tribunal do Santo Ofício. DIVERSIDADE RELIGIOSA , v. 8, p. 51-68, 2018.

BERWANGER, A. R.; LEAL, J. E. F. Normas Técnicas para Transcrição e Edição de Documentos Manuscritos. In: Noções de Paleografia e de Diplomática. $5^{\mathrm{a}}$ ed. Santa Maria: Editora UFSM, 2015. p. 97-106.

FARIA, P. S. de. Os franciscanos e a Inquisição de Goa (século XVII). In: XIV Encontro Regional da ANPUH Rio, 2010, Rio de Janeiro. Anais do XIV Encontro Regional da ANPUH Rio, 2010.

TAVARES, C. C. S. ; CALAINHO, Daniela Buono . Um guia de fontes para o estudo da Inquisição portuguesa. In: REMEDÍ, Fernando. (Org.). Las fuentes documentales en la historia social latinoamericana. 1ed. Córdoba: Centro de Estudios Hirstoricos Prof Carlos Segreti, 2015, v. 1. p. 16-29.

Fonte manuscrita

http://objdigital.bn.br/objdigital2/acervo_digital/div_manuscritos/mss1352118/mss1352118_029.pdf 